\title{
A Review on Effect of Variation in Material Composition and Structural Dimensions on Vibrational Behavior of Composite Materials
}

\author{
Rushvika Pawar ${ }^{+*}$, Gaurav Pawar ${ }^{\dagger}$ and Prashant Mahale ${ }^{\dagger}$ \\ ${ }^{\dagger}$ Department of Mechanical Engineering, MIT College of Engineering, Pune, India \\ Accepted 02 March 2016, Available online 15 March 2016, Special Issue-4 (March 2016)
}

\begin{abstract}
Nowadays, there has been a search for alternatives to steel and alloys for several years, to combat the high cost of repair and maintenance of structures damaged by corrosion and heavy use. Structures made from composite materials are rapidly replacing metallic ones in every field because of their high strength-to-mass ratio. The increasing use of tailored composite materials in the design of important structural elements has necessitated the study of vibrational behavior of composite materials. Therefore different materials together are studied and optimum value of their composition and dimensions are to be formulated. This paper mainly deals with effect of variation in material composition and structural dimensions on vibrational behavior of composite materials.
\end{abstract}

Keywords: vibrational behavior, composite materials

\section{Introduction}

Composite materials, often shortened to composites or composition of materials, are engineered or naturally occurring materials made from two or more constituent materials with significantly different physical or chemical properties which remain separate and distinct at the macroscopic or microscopic scale within the finished structure. Wood is a natural composite of Cellulose fibers in a matrix of lignin. The earliest man-made composite materials were straw and mud combined to form bricks for building construction. The ancient brickmaking process can still be seen on Egyptian tomb paintings in the Metropolitan Museum of Art. Composites are made up of individual materials referred to as constituent materials. There are two categories of constituent materials: matrix and reinforcement. At least one portion of each type is required. The matrix material surrounds and supports the reinforcement materials by maintaining their relative positions. The reinforcements impart their special mechanical and physical properties to enhance the matrix properties. A synergism produces material properties unavailable from the individual constituent materials, while the wide variety of matrix and strengthening materials allows the designer of the product or structure to choose an optimum combination. Engineered composite materials must be formed to shape. The matrix material can be introduced to the reinforcement before or after the reinforcement material is placed into the mold cavity or onto the mold surface. The matrix material experiences a melding event, after which the part shape is essentially set. Depending upon the nature of the matrix material, this melding event can occur in various ways such as chemical polymerization or solidification from the melted state. Most commercially produced composites use a polymer matrix material often called a resin solution. There are many different polymers available depending upon the starting raw ingredients. There are several broad categories, each with numerous variations. The most common are known as polyester, vinyl ester, epoxy, phenolic, polyimide, polyamide, polypropylene, PEEK, Polyethylene and others. The reinforcement materials are often fibers but also commonly ground minerals. The properties can be monitored by varying the resin content of the final product or the fiber content thereby better mechanical property can be achieved for vibration arresting. The term polymer is derived from two Greek words "poly" means many and the term "mer" means parts or units. Thus polymers are composed of a large number of repeating units of small molecule called monomers. In this research selection of polymer which is the toughest task was made based on the requirements for a composite material to achieve the need for study.

\section{Fibers and its Types}

Fiber (also spelled fibre) is classes of materials that are continuous filaments or are in discrete elongated pieces, similar to lengths of thread. They are very important in the biology of both plants and animals, for holding tissues together. Human uses for fibers are diverse. This can be spun into filaments, string, or rope, 
used as a component of composite materials, or matted into sheets to make products such as paper or felt. Fibers are often used in the manufacture of other materials. The strongest engineering materials are generally made as fibers, for example carbon fiber and Ultra-high-molecular-weight polyethylene. Synthetic fibers can often be produced very cheaply and in large amounts compared to natural fibers, but for clothing natural fibers can give some benefits, such as comfort, over their synthetic counterparts. Classification of fibers is shown in Fig.1

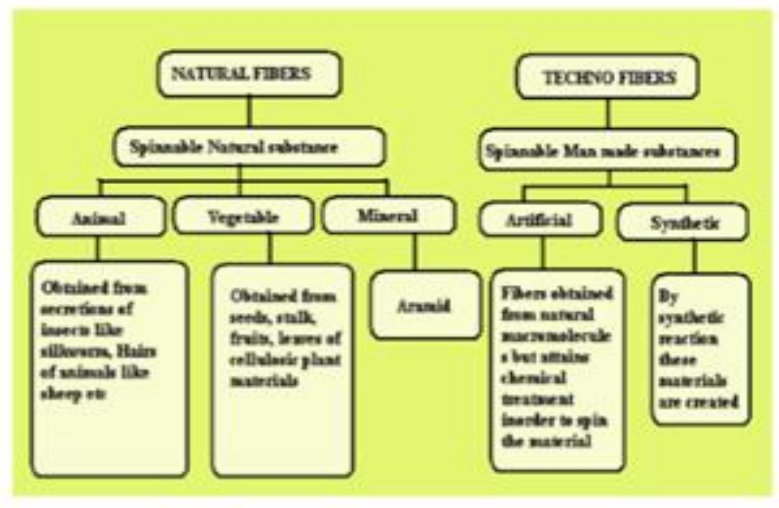

Fig.1. Fiber Classifications

\subsection{Natural Fibers}

Natural fibers include those produced by plants, animals, and geological processes. They are biodegradable over time. They can be classified according to their origin: Vegetable fibers are generally based on arrangements of cellulose; often with lignin examples include cotton, hemp, jute, flax, ramie, and sisal. Plant fibers are employed in the manufacture of paper and textile (cloth), and dietary fiber is an important component of human nutrition. Wood fiber, distinguished from vegetable fiber, is from tree sources. Forms include ground wood, thermo mechanical pulp (TMP) and bleached or unbleached kraft or sulfite pulps. Kraft and sulfite, also called sulphite, refer to the type of pulping process used to remove the lignin bonding the original wood structure, thus freeing the fibers for use in paper and engineered wood products such as fiber board. Animal fibers consist largely of particular proteins. Instances are spider silk, sinew, catgut, wool and hair such as cashmere, mohair and angora, fur such as sheepskin, rabbit, mink, fox, beaver, etc. Mineral fibers include the asbestos group. Asbestos is the only naturally occurring long mineral fiber. Six minerals have been classified as "asbestos" including chrysotile of the serpentine class and those belonging to the amphibole class: amosite, crocidolite, tremolite, anthophyllite and actinolite. Short, fiber-like minerals include wollastonite and attapulgite.

\subsection{Synthetic Fibers}

Synthetic fibers are manufactured from natural cellulose, including rayon, modal, and Lyocell.
Cellulose-based fibers are of two types, regenerated or pure cellulose such as from the cupro-ammonium process and modified cellulose such as the cellulose acetates. Fiber classification in reinforced plastics falls into two classes:

- short fibers, also known as discontinuous fibers, with a general aspect ratio (defined as the ratio of fiber length to diameter) between 20 to 60, and - long fibers, also known as continuous fibers; the general aspect ratio is between 200 to 500 .

\section{The Difference between Natural and Synthetic Fibers}

\subsection{Natural Fiber Properties}

Natural fibers are obtained from plants or animals. It is an environmentally friendly choice for sewing projects because the fabric is created from renewable resources. Cotton, linen, wool, and silk are fabrics made with natural fibers The most common types of animals used in created natural fiber fabrics are sheep, alpacas, and silkworm, but other animals like goats and rabbits are also used. There is a variety of different plants used in creating natural fabrics. Cotton is, by far, the most commonly used plant in making natural fabric. Bamboo is becoming increasingly popular because of its fast rate of renewal. Other plants used in creating natural fabrics are flax, hemp, and pineapple leaves.

\subsection{Synthetic Fiber Properties}

Synthetic fibers are a man-made product created through a chemical process. Chemicals are forced into spinnerets, which have tiny holes where the synthetic fibers are created. Polyester is the most common synthetic fabric created, but there is a huge list of other man-made fabrics. Acetate, nylon, and spandex are commonly used synthetic fabrics. Synthetic fabrics have a huge advantage over natural fabrics because they are more durable. Natural fabrics, however, are better for beginners because they are easier to sew on. In general, the type of project should be taken into consideration before deciding whether a natural or synthetic fabric should be used.

\section{Materials}

\subsection{Natural Fibers}

\subsubsection{Jute Fiber Reinforced Polyethylene}

Natural jute fiber reinforced polymeric composite is fabricated by closed-mold system. To make jute fiber composite, the fibers are weighed according to the fiber volume ratio. To maintain homogeneity, the fibers are arranged systematically according to the weight. Firstly, they are divided in two groups and knitted together as like a fabric mesh which represents a layer. The procedure is repeated for second layers. Both layers are separated by polymeric resins. 


\subsubsection{Jute Fiber Reinforced Epoxy Resins}

The Jute nano-fibers with varying percentage weight (1wt. \% to $5 \mathrm{wt}$. \%) reinforced in epoxy resins to prepare nano-fiber composites by hand lay-up technique. The composites were prepared by using glass fiber woven mat and epoxy resin with $50 \mathrm{wt} . \%$ / 50 wt.\% fraction. The epoxy resin is reinforced with different weight percentage of Jute nano-fiber reinforcing $(0,1,2,3,4$ and 5 wt. \%) are uniformly mixed with epoxy resins mechanically.

\subsection{Synthetic Fiber}

\subsubsection{Granite Epoxy Resins}

Granite epoxy composite is a novel material being developed as an alternate material for precision machine tool beds. Mixing and bonding together carefully selected mix of correctly graded granite aggregate, epoxy resin and curing or hardening agent forms granite epoxy composite. Increase in granite aggregate portion in the mixture within practical limits minimizes the epoxy content and production cost can be reduced.

\subsubsection{Granite Epoxy with Cast Iron Powder}

Granite Epoxy is prepared by conventional process as mentioned above just during the process of final setting the composite, fine cast iron powder is added in the composite. This slight addition of cast iron changes the properties of previous composite at a very great extent.

\section{Vibrational Behavior for Different Variations}

\subsection{Natural Fibers}

\subsubsection{Jute Fiber Reinforced Polyethylene}

Vibration testing is accomplished by introducing a forcing function into a structure, usually with a special type of vibrator. Alternately, a DUT (device under test) is attached to the "table" of a shaker. For relatively low frequency forcing, servo hydraulic (electro hydraulic) shakers are used. For higher frequencies, electro dynamic shakers are used.

Note: In this article the step by step mathematical derivations will not be included, but will focus on the major equations and concepts in vibration analysis. Please refer to the references at the end of the article for detailed derivations

A Damping Factor vs. Foam thickness graph is plotted which gives us complete idea that at a particular ( $4 \mathrm{~mm})$ foam thickness damping factor is minimum.

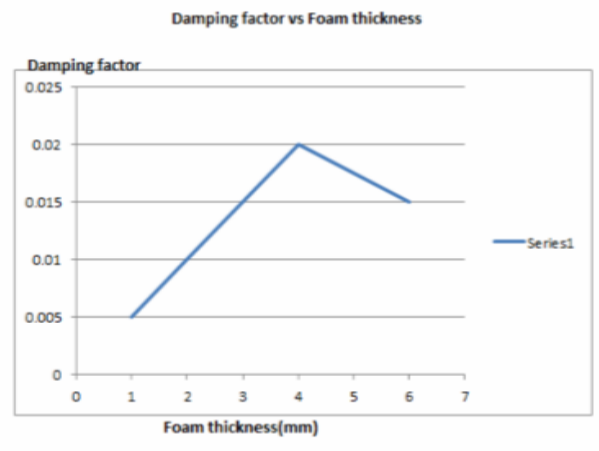

Fig.2. Damping Factor vs. Foam thickness

\subsubsection{Jute Fiber Reinforced Epoxy Resins}

The damping behavior of jute nano-fiber reinforced polymer composite is investigated experimentally with different weight percentage of composites at different modes. The natural frequency increases with the nanofiber reinforcement as compared with the base composite. The improvement in the natural frequency as noticed for both modes of nano-fiber composites (1 wt.\% to 5 wt.\% JNF) when compared with base composite. The increased natural frequency is due to the good dispersion of Jute nano-fiber reinforcement in the matrix which results in improved stiffness.

Table.1 Natural Frequencies and Damping ratios of base composite and Jute nano-fiber Composites

\begin{tabular}{|c|c|c|c|c|}
\hline S.No & Composites & Modes & $\begin{array}{c}\text { Natural } \\
\text { frequency } \\
(\mathbf{H z})\end{array}$ & $\begin{array}{c}\text { Damping } \\
\text { ratio }\end{array}$ \\
\hline 1 & Base composite & 2 & 104 & 0.018 \\
\hline 2 & $\mathrm{BC}+1$ wt.\% JNFC & 2 & 121 & 0.024 \\
\hline 3 & $\mathrm{BC}+2$ wt.\% JNFC & 2 & 167 & 0.027 \\
\hline 4 & $\mathrm{BC}+3$ wt.\% JNFC & 2 & 183 & 0.030 \\
\hline 5 & $\mathrm{BC}+4$ wt.\% JNFC & 2 & 214 & 0.026 \\
\hline 6 & $\mathrm{BC}+5$ wt.\% JNFC & 2 & 204 & 0.023 \\
\hline
\end{tabular}

From the experimental data mentioned in the Table 1, an improvement in natural frequency is noticed in the Jute nano-fibers reinforced composites when compared with base composite.

\subsection{Synthetic Fiber}

\subsubsection{Granite Epoxy Resins}

The FRFs shown in Fig.3 show a difference in the damping characteristics of the specimens and Gr-Ep specimen with $12.5 \%$ resin showed highest damping. These observations are tabulated in table2

The graph shown in Fig 5 shows variation in modal damping with variation in composition of Gr-Ep composite which shows average modal damping of specimen with $12.5 \%$ resin is higher than others. 


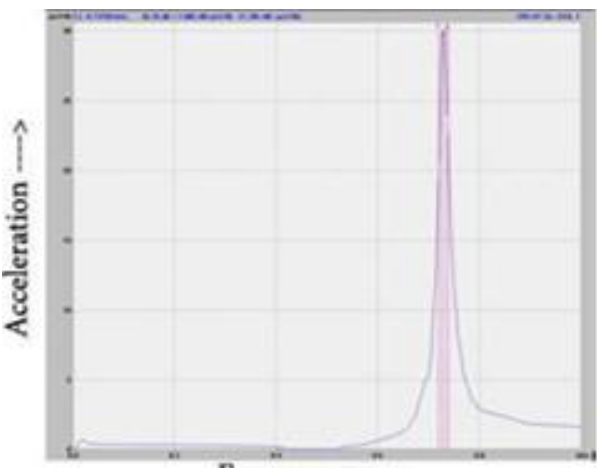

Frequency $\rightarrow$

(a)

Fig.4. (a) FRF of Granite Epoxy (11\% Resin)

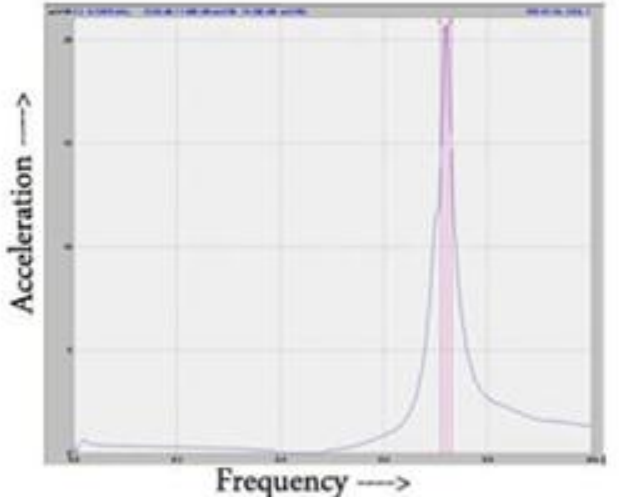

(b)

Fig.4. (b) FRF of Granite Epoxy (12.5\% Resin)

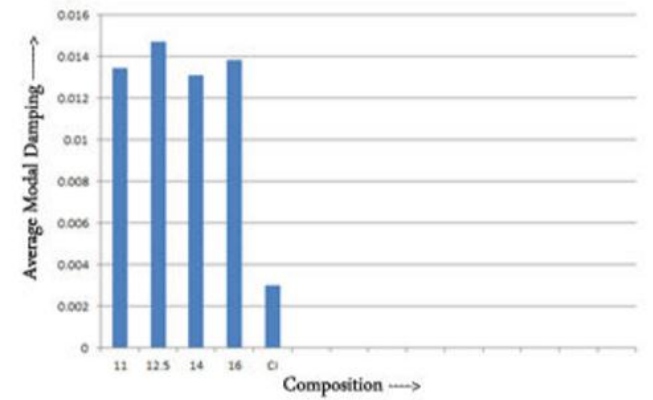

Fig. 3. Graph showing Average Modal damping Vs. GrEp composition

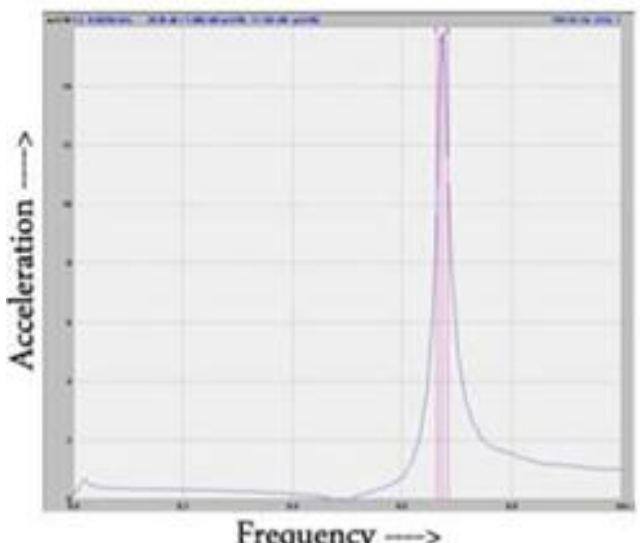

(c)

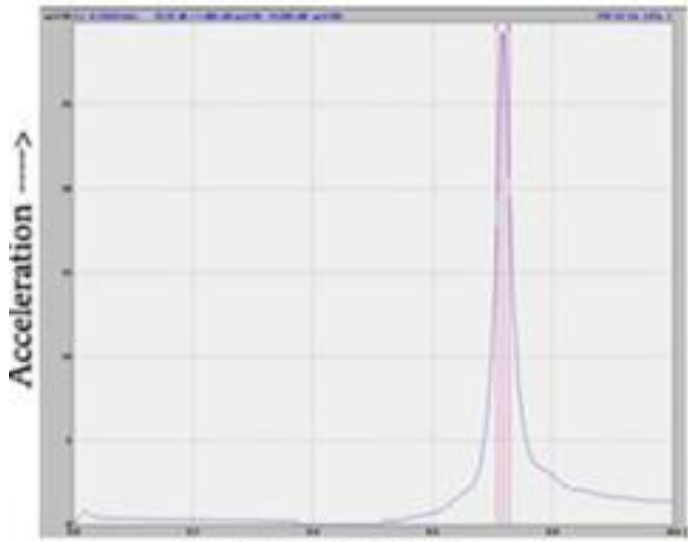

Frequency $\rightarrow$

(d)

Fig.4. (d) FRF of Granite Epoxy (16\% Resin)

Table.2 Average natural frequency at different percentage of resins

\begin{tabular}{|c|c|c|c|c|}
\hline $\begin{array}{l}\text { SI } \\
\text { No. }\end{array}$ & $\begin{array}{l}\text { Granite } \\
\text { epoxy } \\
\text { (\% } \\
\text { Resin) }\end{array}$ & $\begin{array}{l}\text { Specime } \\
\mathbf{n}\end{array}$ & $\begin{array}{l}\text { Natural } \\
\text { Frequenc } \\
y \text { in } \mathbf{H z} \text {, } \\
\omega\end{array}$ & $\begin{array}{l}\text { Average } \\
\text { Natural } \\
\text { Frequency } \\
\text { in Hz }\end{array}$ \\
\hline \multirow[t]{2}{*}{1} & \multirow[t]{2}{*}{11} & 1 & 728.75 & \multirow[t]{2}{*}{730.625} \\
\hline & & 2 & 732.50 & \\
\hline \multirow[t]{2}{*}{2} & \multirow[t]{2}{*}{12.5} & 1 & 685.00 & \multirow[t]{2}{*}{701.875} \\
\hline & & 2 & 718.75 & \\
\hline \multirow[t]{2}{*}{3} & \multirow[t]{2}{*}{14} & 1 & 716.25 & \multirow[t]{2}{*}{736.25} \\
\hline & & 2 & 756.25 & \\
\hline \multirow[t]{2}{*}{4} & \multirow[t]{2}{*}{16} & 1 & 653.75 & \multirow[t]{2}{*}{663.125} \\
\hline & & 2 & 672.50 & \\
\hline
\end{tabular}

\subsubsection{Granite Epoxy with Cast Iron Powder}

This graph shows that high damping capacity of cast iron is one of the most valuable qualities of this material. For this reason it is ideally suited for machine bases and supports, engine cylinder blocks and brake components. The damping capacity of cast iron is considerably greater than that of steel or other kinds of iron. This set of experiments was conducted to study the effect of fine CI powder of 0.075 micron size on the damping properties of Gr-Ep composites.

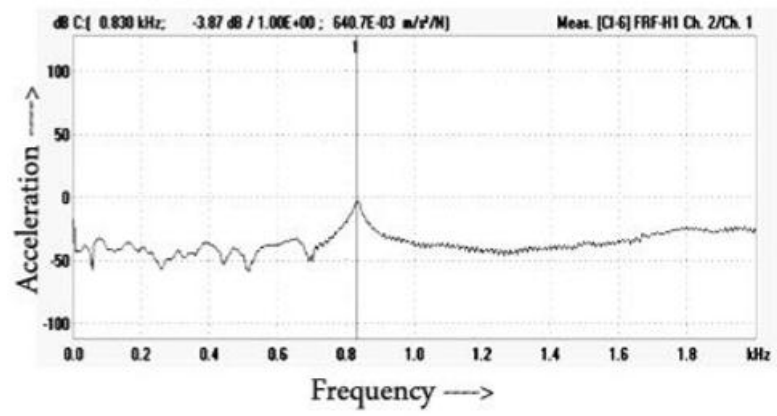

Fig.5. Acceleration vs. Frequency

Fig.4. (c) FRF of Granite Epoxy (14\% Resin) 


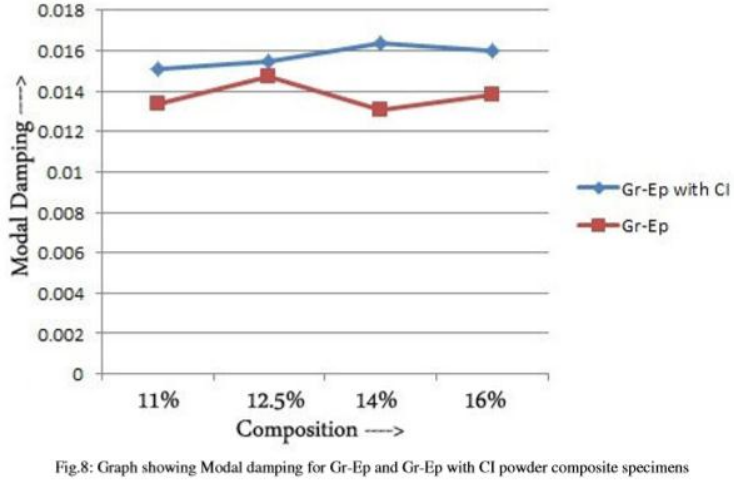

Fig.6 Modal Damping vs. Composition

\section{Conclusion}

The damping behavior of various composite materials is studied and results have been formulated above. The effects of different natural and synthetic reinforced composite materials were studied.

- Natural fibers due to its technical superiority over the synthetic fibers have proved that it is a versatile material for application in rural areas to high tech applications.

- Variation in thickness, i.e., dimensional variation of jute reinforced polyethylene showed that maximum damping factor can be obtained at particular dimensions.
- Also we have seen that when compositions of reinforcement materials are varied the damping factor changes and also we have found that at specific composition we get highest damping capacity.

- Similarly, adding some different materials, like cast iron in this case have improved damping capacity of the already existing composite materials.

\section{References}

N.Abilash et.al, (2011), Evolution of Experimental study on Bamboo based FRP composites.

A.Grozdanov et.al, (2007), Rice straw as an alternative reinforcement in polypropylene composites, Australian journal of crop science.

K. Murali Mohan Rao et.al, (2010), Extraction and tensile properties of natural fibres Vakka, date and bamboo. Materials and design 31 508-513.

P.J.Herrera-Franco et.al, (2005), A study of mechanical properties of Short natural fibre reinforced composites. Composites: Part: B 36 597-608.

Khosrow Ghavami, (2005), Bamboo as reinforcement in structural concrete elements. Concrete composites 27637 649.

Anil N. Netravali et.al, (2003), Composites get greener. Elsevier science.

Valadez-Gonzalez et.al, (1999) Effect of fibre surface treatment on the fibre-matrix bond strength of natural fibre reinforced composites. Composites Part: B 30309 320.

Navin Chand et.al, (2007), High stress abrasive wear study on bamboo. Wear 26 1031-1037. 